\title{
Patient with Antineutrophil Cytoplasmic Antibody Associated Small Vessel Vasculitis, Acute Renal Failure, and Coronavirus Disease-19 Pneumonia: A Diagnostic and Therapeutic Challenge
}

\author{
Biljana Gerasimovska-Kitanovska*, Gjulshen Selim¹, Zvezdana Petronijevik¹, Blagica Pecanova ${ }^{2}$, Gjorgi Stojchev², \\ Natasha Eftimovska-Otovic ${ }^{3}$, Marija Zdravevska ${ }^{4}$, Elena Jovanovska-Janeva ${ }^{4}$, Dubravka Antova ${ }^{5}$, Elena Curakova ${ }^{6}$ \\ ${ }^{1}$ Department of Internal Medicine, University Clinic of Nephrology, Medical Faculty, Ss. Cyril and Methodius University, Skopje, \\ Republic of Macedonia; ${ }^{2}$ General Hospital, Strumica, Republic of Macedonia; ${ }^{3}$ Department of Internal Medicine, General City \\ Hospital, Skopje, Republic of Macedonia; ${ }^{4}$ Department of Internal Medicine, University Clinic of Pulmonology and Allergology, \\ Medical Faculty, Ss. Cyril and Methodius University, Skopje, Republic of Macedonia; ${ }^{5}$ Department of Internal Medicine, University \\ Clinic of Rheumatology, Medical Faculty, Ss. Cyril and Methodius University, Skopje, Republic of Macedonia; ${ }^{6}$ Department of \\ Internal Medicine, University Clinic of Gastroenterohepatology, Medical Faculty, Ss. Cyril and Methodius University, Skopje, \\ Republic of Macedonia
}

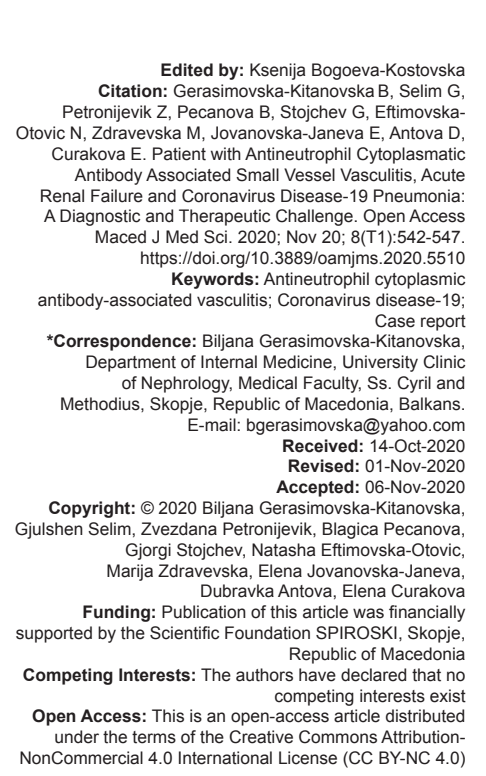

Introduction

Antineutrophil cytoplasmatic antibody (ANCA)associated vasculitis (AAV) is a rare group of multisystem disorders, affecting 13-25 people per million population in Europe [1]. It is characterized by inflammation, destruction of small and medium-sized blood vessels, and presence of circulating ANCA's. Clinical disease phenotype includes granulomatosis with polyangiitis, microscopic polyangiitis, eosinophilic granulomatosis with polyangiitis, and renal-limited vasculitis [2]. ANCA$\mathrm{AAV}$ has a predilection for the kidney and more than three quarters of patients have renal involvement with rapidly progressive glomerulonephritis [3]. Small-vessel systemic vasculitis may present as pulmonary renal syndrome and is characterized by necrotizing glomerulonephritis and pulmonary hemorrhage [4].

Diagnosis of a patient with de-novo ANCAAAV during coronavirus disease (COVID)-19 pandemic is a challenge [5]. Clinical presentation of patients with AAV may overlap with manifestations of COVID-19 infection [6]. Pulmonary affection and acute kidney injury may occur as a result of AAV or as a presentation of COVID-19 infection [7]. Furthermore, cytokine-release syndrome, as a systemic inflammatory response which may occur in COVID-19 disease, may mimic vasculitis [8]. It is important to distinguish accurately between vasculitis and infection to provide adequate 
and timely therapy. Therapy for AAV in COVID-19 requires multi-disciplinary collaboration due to the risks associated with immunosuppressive medications.

\section{Case Report}

A69-year-old non-smoker, non-diabetic female, presented in the outpatient unit at the department of pulmonology with dry cough, malaise, and sub-febrile temperature, lasting for 1 month. She was treated with a combination of two antibiotics (azithromycin and ceftriaxone) without improvement of the situation. There was no positive family history. She gave a history of allergy to non-steroidal anti-inflammatory drug and a history of sensorineural hearing loss, needing a hearing aid for 2 years. Dry, age-related macular degeneration was diagnosed in 2017 and she had a history of pneumonia in 2017 and 2019. Chest examination at check-up revealed an auscultation finding of vesicular respiration with bronchial crackling sounds bilaterally in the basal parts.

Due to persistent symptoms, a chest X-ray and computed tomography (CT) scan were performed with a finding of parenchymal consolidation on the basis of the right lobe in continuity with the lower part of the right hilum and pronounced peri-bronchial changes bilaterally. The heart, aorta, and major blood vessels and central pulmonary arteries were patent without evident emboli. Four tests for COVID-19 were made, all negative.

The patient was admitted in the department of pulmonology. The microbiological results from sputum were negative and tests such as anti-nuclear antibodies HEp-2 (indirect fluorescence assay), antidouble-stranded deoxyribonucleic acid, and c-ANCA were all negative. p-ANCA immunological test was positive, pneumonia panel plus test was negative, hantavirus immunoglobulin (lg) lgM was negative, rapid test for Mycobacterium tuberculosis was negative on two separate occasions, and the Löwenstein-Jensen medium was negative. Procalcitonine level was $0.4 \mathrm{ng} / \mathrm{ml}$ (ref. value 0, $15 \mathrm{ng} / \mathrm{ml}$ ).

Due to the rapid increase of serum creatinine from $65 \mathrm{umol} / \mathrm{l}$ to $695 \mathrm{umol} / \mathrm{L}$ and serum urea $13 \mathrm{mmol} / \mathrm{L}$ (normal range of serum creatinine 45-109 umol/L and serum urea $2,7-7,8 \mathrm{mmol} / \mathrm{L})$ on the $7^{\text {th }}$ day of the hospitalization, a femoral venous catheter was placed, and the next day the first dialysis was performed. Urinary analysis showed proteins and blood in the urine. Affection of multiple systems and ANCA positivity implied the use of Birmingham vasculitis activity score (BVAS) as an index of severity of disease and it was 17.

All efforts to obtain tissue biopsy failed. Invasive lung investigations were not possible due to the overall estimation of risk as very high. Renal biopsy was not possible due to prolonged bleeding time. Nasal endoscopy was indicated. Unfortunately, no granulomatous disease-associated lesions in the nasal cavities were found and biopsy was not done.

The patient was transferred to our department of nephrology on the $9^{\text {th }}$ day of the hospitalization at the department of pulmonology, with high suspicion of pulmonary-renal syndrome, ANCA-AAV, and acute renal failure requiring hemodialysis.

On transfer, the patient still complained of shortness of breath and had hematuria. General examination of the patient revealed an alert and conscious patient with pale skin. On admission, the patient was hypertensive $(165 / 90 \mathrm{mmHg})$, tachycardic (123 bpm), and hypoxic (oxygen saturation on room air $85 \%$ ) and had no visible swelling on the lower extremities. Chest examination revealed an auscultation finding of vesicular respiration with bronchial crackling sounds bilaterally in the basal parts. Examination of other systems was unremarkable. The BVAS score in our department was calculated as 33.

The blood tests on admission demonstrated renal impairment with a creatinine of $364 \mathrm{umol} / \mathrm{L}$, an ongoing acute inflammatory response with C-reactive protein (CRP) $205 \mathrm{mg} / \mathrm{L}$, leukocytosis $17.5\left(10^{9} / \mathrm{L}\right)$, lymphocytopenia $8.2 \%$, anemia red blood cell (RBC), hemoglobin (HGB), (RBC 2.5; HGB 72; hematocrit 0.2), serum albumins $27 \mathrm{~g} / \mathrm{L}$, and total protein $56 \mathrm{~g} / \mathrm{L}$. Urinalysis demonstrated blood and protein on dipstick testing. Proteinuria of $3.5 \mathrm{~g} / \mathrm{dU}$ was confirmed. Immunological status of the patient: $\operatorname{lgM}, \lg E, \lg G, \lg A$, $\mathrm{C} 3$, and C4 levels were normal. Anti-glioblastoma was negative. COVID-19 polymerase chain reaction (PCR) test at admission at the department was negative. Viral markers for hepatitis $\mathrm{B}$ and $\mathrm{C}$ were negative.

An ultrasound of the kidneys and urogenital tract was performed with the following finding: Both kidneys with normal ultrasound shape and placement with no pathological findings, urinary bladder unremarkable.

A CT lung scan on the day of admission in our department was indicated and revealed an evident progression of finding demonstrated with diffuse centrilobular ground-glass opacities dominantly in upper lobes and an alveolar consolidation, as well as in apicobasal and in the right basal segments with patchy nodular lesions. On the right side, there was an anterior subsegmental and posterobasal consolidation and small pleural effusion. Findings were suggestive for alveolar hemorrhage consistent with autoimmune disease-vasculitis (Figure 1).

Immediately upon transfer of the patient at the department of nephrology, patients' oxygen saturation dropped to $70 \%$. Oxygen therapy was commenced and continued throughout her stay in the hospital. After obtaining the CT scan finding, induction therapy was started for the treatment of ANCA positive AAV. 
Several diagnostic tests were done out of the hospital building. The patient received intravenous pulse methylprednisolone therapy in a dosage of $500 \mathrm{mg}$ per day for 3 days, continued with oral prednisolone, slowly tapered to $60 \mathrm{mg}$ per day. An intravenous drip of cyclophosphamide $500 \mathrm{mg}$ was administered. Due to the alveolar hemorrhage, plasmapheresis treatment was started. Seven sessions were planned, but only 4 were performed due to further aggravation of the situation. Plasmaphereses and hemodialysis sessions were performed on an alternate day. With this treatment and oxygen support, saturation started to rise and reached $90 \%$. In addition to this treatment an antihypertensive drug (a calcium antagonist) and an inhibitor of the gastric proton pump were administered. Urine culture revealed Enterococcus and treatment was started with amp. tazobactam a 4, $5 \mathrm{~g} / 12 \mathrm{~h}$, according to an antibiogram.

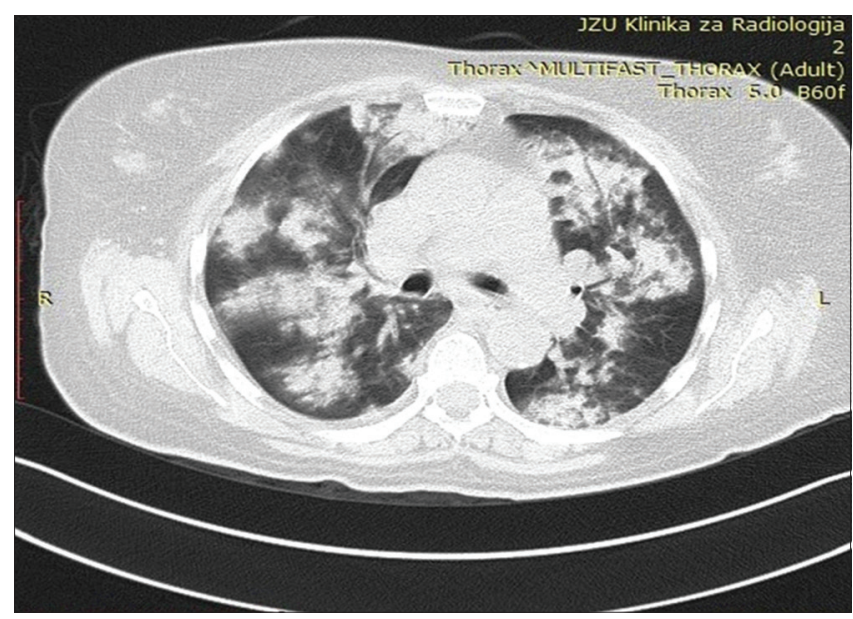

Figure 1: Findings of computed tomography lung scan at admission in the department of nephrology were suggestive for diffuse alveolar hemorrhage

Due to activated fibrinolysis (elevated levels of D-dimer - 9024), low molecular dose of heparin (amp. Clexane a $40 \mathrm{mg}$ per day) was started. Two units of RBCs were administered during the hospitalization.

After 11 days of hospitalization in our unit, the inflammatory markers of the patient were in decline: CRP $20 \mathrm{mg} / \mathrm{L}$; white blood cell 11, 5, but there was persistent anemia even after transfusion with two doses of RBC (HGB 95; RBC 3, 2). During the hospitalization period, the patient was afebrile and circulatory stable.

After 12 days of hospital treatment and a requirement to repeat the cycle of cyclophosphamide at the $14^{\text {th }}$ day, and a newly stated complaint of pharyngeal dryness and drop of HGB to $72 \mathrm{~g} / \mathrm{l}$, a control nasal swab for PCR test was taken for severe acute respiratory syndrome coronavirus 2 (SARS-COV-2), which turned out positive. Serological IgM and IgG tests for SARSCOV-2 were negative. Plasma exchanges were discontinued due to the co-infection with COVID-19.

According to the protocol, the patient was transferred to a COVID-19 hospital. Discharge diagnosis included pulmorenal syndrome, acute renal failure stage 3, treatment with hemodialysis, ANCA$\mathrm{AAV}$, alveolar hemorrhage treated with plasmapheresis, anemic syndrome, urinary infection with Enterococcus, and infection with COVID-19.

The patient was first transferred to the infectious diseases unit in the general city hospital and diagnosed with COVID-19 pneumonia. Another reverse transcription PCR (RT-PCR) test for SARSCOV-2 taken upon admission was also positive. Initial laboratory tests were made on admission and revealed persistent anemia and hypoalbuminemia.

There the hemodialysis treatment continued. CT angiography of the pulmonary truncus showed bilateral diffuse zones of interstitial consolidation (Figure 2). Multiple lymph nodes were seen in the mediastinum. Visualization of the main pulmonary truncus (Figure 3) and pulmonary arteries showed no alterations in the hemodynamic flow and no endoluminal thrombotic masses. No alterations of the blood flow were seen in the segmental pulmonary branches, but subsegmental branches were not visible because of massive consolidation.

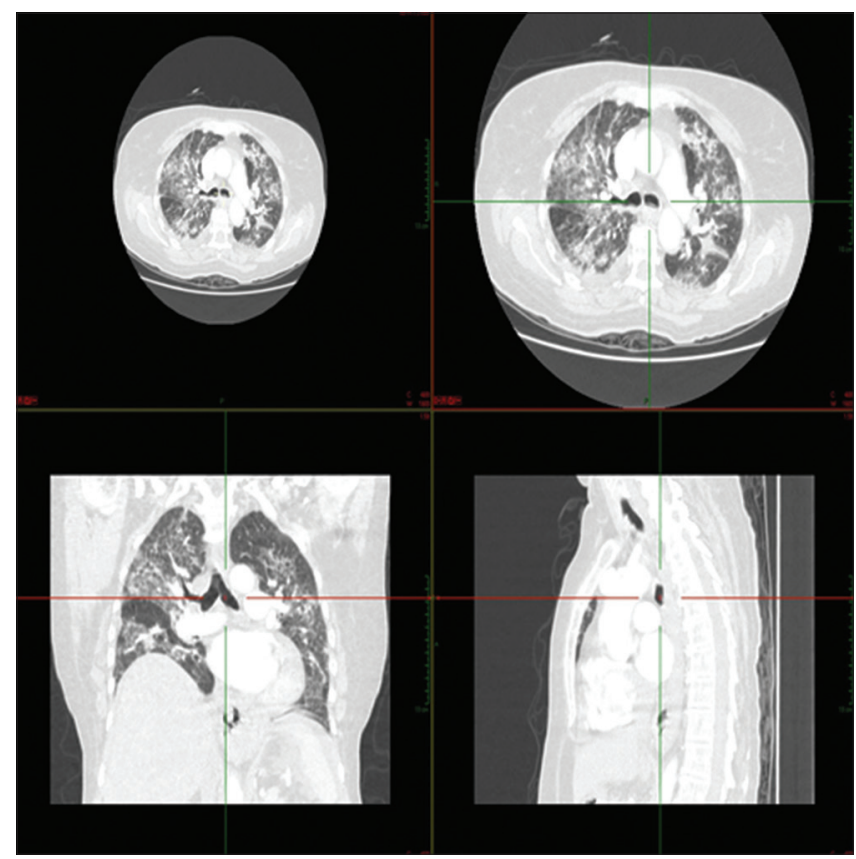

Figure 2: Bilateral diffuse zones of consolidation

Pulmonary X-ray showed massive zones of parenchymal consolidations in the apical, middle, and basal parts of both lungs.

Because of the severe general health condition, the patient was transferred to the intensive care unit, was intubated, and put on a mechanical ventilator. She was oligoanuric and under continuous inotrope stimulation. The laboratory tests revealed an increase in interleukin 6 (IL-6) $(30 \mathrm{pg} / \mathrm{ml})$; ferritin> 612; and procalcitonin $2,13 \mathrm{ng} / \mathrm{ml}$.

Acinetobacter was identified in the tracheal aspirate. She was treated with triple antibiotic therapy (Meropenem, Linezolid, and Colistin). An 
infectious disease specialist was consulted and tocilizumab was added to the medication list. The patient was also treated with packed RBCs, fresh frozen plasma, convalescent plasma, ozone therapy, anticoagulant, and gastroprotective therapy. In spite of treatment and used measures for cardiopulmonary resuscitation, death occurred on the $33^{\text {rd }}$ day of her first hospitalization.

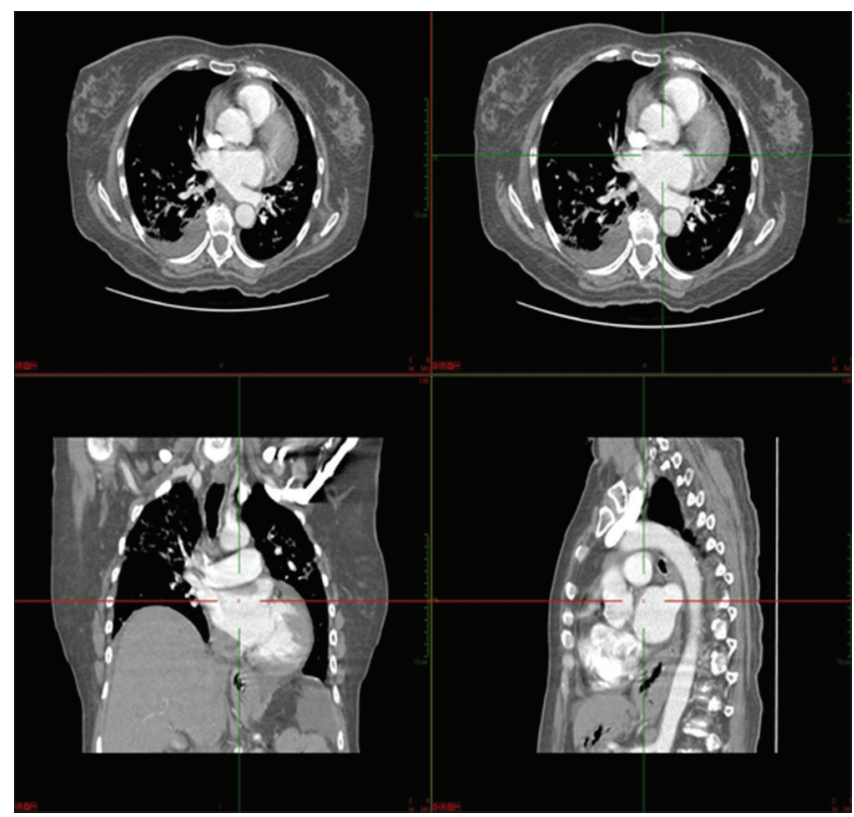

Figure 3: Absence of thrombotic masses

\section{Discussion}

Our patient had a pulmonary-renal syndrome and severe ANCA-associated renal involvement, complicated with COVID-19 pneumonia.

The exact clinical phenotype of the AAV could not be determined, since tissue biopsy was cancelled, due to the severity of the general condition and prolonged bleeding time. A 3-year history of sensorineural loss of hearing, macular degeneration, pneumonia, and allergies may imply isolated affection of several organs as part of vasculitis. There were no signs of highly active disease in her medical history. Although an uncommon finding, these findings were suggestive of microscopic polyangiitis in the absence of granulomas and more destructive local changes [9].

For at least a month before hospitalization, there were non-specific constitutional presentations such as malaise, low-grade temperature, and diarrhea. Progression of the pulmonary and kidney injury, with alveolar hemorrhage and rapid progressive glomerulonephritis, together with the myeloperoxidase (MPO) positivity and high score of disease activity BVAS, led to diagnosis of AAV. Microscopic polyangiitis was the most probable phenotype in our patient. This finding is not unexpected, according to a study which reported that in a 20-year population-based cohort of patients with AAVglomerulonephritis, $65 \%$ had microscopic polyangiitis, and $74 \%$ were MPO-ANCA positive [10].

Recent reports showed that ANCA antibodies are not only a biomarker of AAV but are involved in the pathogenesis of the renal involvement in AAV. Binding of MPO or proteinase 3 antibodies to autoantigens activates neutrophils, that degranulate and release reactive oxygen species [11]. Neutrophil extracellular traps (NETs) are released to contain infections, but if they are not properly regulated, they damage the endothelium and activate complement, thus provoking inflammation and microvascular thrombosis, explained as ANCA-cytokine sequence theory [12], [13]. Unregulated NETs are also involved in COVID-19 pneumonia and lead to a very fast progression of lung destruction [14].

According to the grading recommended by the European vasculitis study group, the patient had a high index of activity of the disease, with life-threatening diffuse alveolar hemorrhage [15]. Severity of disease implied immediate commencement of therapy. Standard of care for induction therapy in severe AAV includes a combination of glucocorticoids with either cyclophosphamide or rituximab [2]. Although autoimmune patients receiving immunosuppressive therapy may be prone to COVID-19 infection, it is contraindicated to delay therapy [16]. The management of glomerular diseases in the COVID-19 era is changing, and there are issues whether intravenous cyclophosphamide should be substituted with peroral or rituximab should not be used at all due to longterm depletion of B cells [17]. There are recently some case reports where rituximab was used successfully in patients with AAV [18]. The most recent paper for treatment of AAV during COVID pandemics recommends plasma exchange, oral glucocorticoids, and intravenous cyclophosphamide 500 mg every 2-3 weeks in 6 doses for COVID-19 negative patients, with several options in COVID-19 positive patients [19].

Single intravenous dose of cyclophosphamide and pulse methylprednisolone for 3 days was administered in our patient. Plasma exchange was instituted based on the findings of serum creatinine above $500 \mu \mathrm{mol} / /$ and diffuse intraalveolar hemorrhage on CT scan, according to the recommendations of the MEPEX trial [20]. Plasma exchange removes the proinflammatory cytokines, complement, and coagulation factors, and dilutes ANCA titers, and may decrease progression to end-stage renal disease [21].

Inflammatory markers, such as CRP, were very high at the beginning of the hospitalization and decreased after induction therapy with corticosteroids and cyclophosphamide. The clinical condition of the patient improved significantly.

Later on in the hospitalization, nasal RT-PCR 
SARS-COV 2 test was positive, and COVID-19 pneumonia soon emerged. We found only one report of false-positive SARS COV 2 RT-PCR test in a patient with $A A V$, potentially due to cross-reactivity [22]. This was not the case with our patient because a positive RT PCR test was confirmed twice and the disease progressed with worsening of the clinical and radiological features.

There is a link between infection and autoimmunity - a higher disease activity may predispose to developing infections. We believe that the high disease activity index predisposed our patient to infection with COVID-19, as well as to urinary infection with Enterobacter. Worsening of the condition was confirmed by an increase in the inflammatory markers, CRP and procalcitonin, and high IL6. Procalcitonin is normal in patients with autoimmune disease and when higher levels are confirmed, it is associated with infection [23]. IL 6, CRP, erythrocyte sedimentation rate, serum ferritin were positively associated with the severity of COVID19, as suggested in literature [24]. High circulating level of D-dimers correlated with the inflammatory markers, representing a hypercoagulable state, associated with the AAV and also with COVID-19 infection [25], [26].

COVID-19 may be responsible for cytokine release syndrome (CRS), as a systemic inflammatory response [27]. SARS-CoV-2 binds to alveolar epithelial cells and results in the release of a large number of cytokines, including IL-6. Treatment of the cytokine storm has become an important part of rescuing severe COVID-19 patients. Tocilizumab as a IL-6 receptor blocker was used as salvage therapy in this patient. Tocilizumab was tried in patients with a severe form of COVID-19 and cytokine storm yet with no significant difference in survival [28].

Although radiological findings of nodules, consolidation, and ground-glass opacities were consistent first with alveolar hemorrhage in vasculitis, the findings progressed into massive zones of consolidation at the next radiological imaging (CT angiography) which was highly suggestive of COVID-19 pneumonia, confirmed by two positive SARS COV2 PCR tests [29].

One of the diagnostic challenges in COVID-19 infection is that it may provoke acute kidney injury and may mimic vasculitis. It was reported that $36.6 \%$ of patients hospitalized for COVID-19 had acute kidney injury, with $14.4 \%$ requiring a registered respiratory therapist. Acute renal failure was registered in patients with respiratory failure on mechanical ventilation and was a predictor of poor outcome [30]. Renal failure may be due to prerenal failure and collapsing glomerulopathy [31]. Recent reports object to the SARS-COV2 nephropathy as a separate entity, as there was an absence of viral genetic material in renal biopsy specimens and no histologic proof for cytopathic effects of the virus [32].

Unfortunately, the severe form of AAV, renal failure, and infections, despite all therapeutic efforts, were predictors of a poor outcome in the patient.

\section{Conclusion}

ANCA positive vasculitis is a rare disease which needs fast and prompt diagnosis and responds well to aggressive treatment with plasmapheresis, pulse dose of corticosteroids, and immunosuppressive drugs. COVID-19 infection is still a rather new and unknown disease, but the CRS that it causes can have a lethal outcome in the complications of the primary disease. Infections are common in immune-compromised patients and the risk is increased with every prolonged stay in the intensive care unit. In COVID-19 pandemic, it is important to diagnose AAV timely and to provide induction therapy as well as to provide treatment for concurrent infections.

\section{References}

1. Watts RA, Mahr A, Mohammad AJ, Gatenby P, Basu N, FloresSuárez LF. Classification, epidemiology and clinical subgrouping of antineutrophil cytoplasmic antibody (ANCA)-associated vasculitis. Nephrol Dial Transplant. 2015;30 Suppl 1:i14-22. https://doi.org/10.1093/ndt/gfv022

PMid:25805746

2. Geetha D, Jefferson JA. ANCA-associated vasculitis: Core curriculum 2020. Am J Kidney Dis. 2020;75(1):124-37. https:// doi.org/10.1053/j.ajkd.2019.04.031

PMid:31358311

3. Rowaiye OO, Kusztal M, Klinger M. The kidneys and ANCAassociated vasculitis: From pathogenesis to diagnosis. Clin Kidney J. 2015;8(3):343-350. https://doi.org/10.1093/ckj/sfv020 PMid:26034600

4. McCabe C, Jones Q, Nikolopoulou A, Wathen C, Luqmani R. Pulmonary-renal syndromes: An update for respiratory physicians. Respir Med. 2011;105(10):1413-21. https://doi. org/10.1016/j.rmed.2011.05.012 PMid:21684732

5. Uppal NN, Kello N, Shah HH, Khanin Y, de Oleo IR, Epstein E, etal De novo ANCA-associated vasculitis with glomerulonephritis in COVID-19. Kidney Int Rep. 2020;5(11):2079-83. https://doi. org/10.1016/j.ekir.2020.08.012

PMid:32839744

6. Giollo A, Bixio R, Gatti D, Viapiana O, Idolazzi L, Dejaco $\mathrm{C}$, et al. Challenge of diagnosing ANCA-associated vasculitis during COVID-19 pandemic: A missed 'window of opportunity. Ann Rheum Dis. 2020. https://doi.org/10.1136/ annrheumdis-2020-218830

PMid:32816699

7. Behzad S, Aghaghazvini L, Radmard AR, Gholamrezanezhad A Extrapulmonary manifestations of COVID-19: Radiologic and clinical overview. Clin Imaging. 2020;66:35-41. https://doi. org/10.1016/j.clinimag.2020.05.013

PMid:32425338

8. Lee DW, Gardner R, Porter DL. Current concepts in the diagnosis and management of cytokine release syndrome. Blood. 2014;124(2):188-95. https://doi.org/10.1182/ blood-2015-07-656918

PMid:31265503 
9. Villiger PM, Guillevin L. Microscopic polyangiitis: Clinical presentation. Autoimmun Rev. 2010;9(12):812-9. PMid:20656070

10. Berti A, Gall EC, Cornec D, Moura MC, Matteson EL, Crowson CS, et al. Incidence, prevalence, mortality and chronic renal damage of anti-neutrophil cytoplasmic antibodyassociated glomerulonephritis in a 20-year population-based cohort. Nephrol Dial Transplant. 2019;34(9):1508-17. https:// doi.org/10.1093/ndt/gfy250

PMid:30102330

11. Masuda S, Nonokawa M, Futamata E, Nishibata Y, Iwasaki S, Tsuji $\mathrm{T}$, et al. Formation and disordered degradation of neutrophil extracellular traps in necrotizing lesions of antineutrophil cytoplasmic antibody-associated vasculitis. Am J Pathol. 2019;189(4):839-46. https://doi.org/10.1016/j. ajpath.2019.01.007

PMid:30677396

12. Csernok E. Anti-neutrophil cytoplasmic antibodies and pathogenesis of small vessel vasculitides. Autoimmun Rev. 2003;2(3):158-64. https://doi.org/10.1016/ s1568-9972(03)00010-7 PMid: 12848957

13. Dąbrowska D, Jabłońska E, Garley M, Sawicka-Powierza J, Nowak K. The phenomenon of neutrophil extracellular traps in vascular diseases. Arch Immunol Ther Exp (Warsz). 2018;66(4):273-81. https://doi.org/10.1007/s00005-018-0505-y PMid:29404659

14. Zuo $Y$, Yalavarthi $S$, Shi H, Gockman $K$, Zuo $M$, Madison JA, et al. Neutrophil extracellular traps in COVID-19. JCI Insight. 2020;5(11):e138999. https://doi. org/10.1101/2020.04.30.20086736 PMid:32329756

15. Yates M, Watts RA, Bajema IM, Cid MC, Crestani B, Hauser T, etal. EULAR/ERA-EDTA recommendations for the management of ANCA-associated vasculitis. Ann Rheum Dis. 2016;75(9):158394. https://doi.org/10.1136/annrheumdis-2016-209133 PMid:27338776

16. The Renal Association, Guidance for Clinicians with Patients Receiving Immunosuppression Treatment for Autoimmune Conditions of their Native Kidneys during COVID-19 Version 2; 2020.

17. Bomback AS, Canetta PA, Ahn W, Ahmad SB, Radhakrishnan J, Appel GB. How COVID-19 has changed the management of glomerular diseases. Clin J Am Soc Nephrol. 2020;15:876-9. https://doi.org/10.2215/cjn.04530420

PMid:32332048

18. Suárez-Díaz S, Morán-Castaño $\mathrm{C}$, Coto-Hernández R, MozoAvellaneda L, Suárez-Cuervo C, Caminal-Montero L, et al. Mild COVID-19 in ANCA-associated vasculitis treated with rituximab. Ann Rheum Dis. 2020. https://doi.org/10.1136/ annrheumdis-2020-218246

PMid:32769153

19. Gapud EJ, Kronbichler A, Gauckler P, Geetha D. Immunotherapy for ANCA-associated vasculitis during the COVID-19 pandemic. Eur J Rheumatol. 2020;7 Suppl 2:S121-8. https://doi. org/10.5152/eurjrheum.2020.2067

PMid:32716836

20. Walsh M, Casian A, Flossmann O, Westman K, Höglund $P$, Pusey $C$, et al. Long-term follow-up of patients with severe ANCA-associated vasculitis comparing plasma exchange to intravenous methylprednisolone treatment is unclear. Kidney Int. 2013;84(2):397-402. https://doi.org/10.1038/ki.2013.131 PMid:23615499

21. Padmanabhan A, Connelly-Smith L, Aqui N, Balogun RA, Klingel $R$, Meyer $E$, et al. Guidelines on the use of therapeutic apheresis in clinical practice-evidence-based approach from the writing committee of the American society for apheresis: The eighth special issue. J Clin Apher. 2019;34(3):171-354. https:// doi.org/10.1002/jca.21705

PMid:31180581

22. Tzouvelekis A, Karampitsakos T, Krompa A, Markozannes E, Bouros D. False positive COVID-19 antibody test in a case of granulomatosis with polyangiitis. Front Med (Lausanne). 2020;7:399. https://doi.org/10.3389/fmed.2020.00399 PMid:32733908

23. Eberhard OK, Haubitz M, Brunkhorst FM, Kliem V, Koch KM, Brunkhorst R. Usefulness of procalcitonin for differentiation between activity of systemic autoimmune disease (systemic lupus erythematosus/systemic antineutrophil cytoplasmic antibody-associated vasculitis) and invasive bacterial infection. Arthritis Rheum. 1997;40(7):1250-6. https://doi. org/10.1002/1529-0131(199707)40:7<1250::aid-art9>3.0.co;2-a PMid:9214425

24. Zeng F, Huang $Y$, Guo $Y$, Yin M, Chen X, Xiao L, et al. Association of inflammatory markers with the severity of COVID-19: A metaanalysis. Int J Infect Dis. 2020;96:467-74.

PMid:32425643

25. Ma TT, Huang YM, Wang C. Coagulation and fibrinolysis index profile in patients with ANCA-associated vasculitis. PLoS One. 2014;9(5):e97843. https://doi.org/10.1371/journal. pone. 0097843

PMid:24842719

26. Yao Y, Cao J, Wang Q, Shi Q, Liu K, Luo Z, et al. D-dimer as a biomarker for disease severity and mortality in COVID-19 patients: A case control study. J Intensive Care. 2020;8:49. https://doi.org/10.1186/s40560-020-00466-z PMid:32665858

27. Zhang $\mathrm{C}, \mathrm{Wu} \mathrm{Z}$, Li JW, Zhao H, Wang GQ. Cytokine release syndrome in severe COVID-19: Interleukin-6 receptor antagonist tocilizumab may be the key to reduce mortality. Int J Antimicrob Agents. 2020;55(5):105954. https://doi.org/10.1016/j. ijantimicag.2020.105954 PMid:32234467

28. Radbel J, Narayanan N, Bhatt PJ. Use of tocilizumab for COVID-19-induced cytokine release syndrome: A cautionary case report. Chest. 2020;158(1):e15-9. https://doi.org/10.1016/j. chest.2020.04.024

PMid:32343968

29. Hani C, Trieu NH, Saab I, Dangeard S, Bennani $\mathrm{S}$, Chassagnon G, et al. COVID-19 pneumonia: A review of typical CT findings and differential diagnosis. Diagn Interv Imaging. 2020;101(5):263-8. https://doi.org/10.1016/j.diii.2020.03.014 PMid:32291197

30. Hirsch JS, Ng JH, Ross DW, Sharma P, Shah HH, Barnett RL, et al. Acute kidney injury in patients hospitalized with COVID-19. Kidney Int. 2020;98(1):209-18.

PMid:32416116

31. Peleg Y, Kudose S, D'Agati V, Siddall E, Ahmad S, Kisselev S, et al. Acute kidney injury due to collapsing glomerulopathy following COVID-19 infection. Kidney Int Rep. 2020;5(6):940-5. https://doi.org/10.1016/j.ekir.2020.04.017 PMid:32346659

32. Rossi GM, Delsante M, Pilato FP, Gnetti L, Gabrielli L, Rossini G, et al. Kidney biopsy findings in a critically III COVID-19 patient with dialysis-dependent acute kidney injury: A case against SARS-CoV-2 nephropathy. Kidney Int Rep. 2020;5(7):1100-5. https://doi.org/10.1016/j.ekir.2020.05.005

PMid:32426558 